\title{
Cooperativismo: desarrollo y organización histórica
}

\section{Cooperativism: development and historical organization}

\author{
ALEJANDRO PAÚL ALDÁS ALARCÓN $(a, b)$ \\ a Pontificia Universidad Católica del Ecuador, Quito - Ecuador, Docente Agregado \\ b Escuela Politécnica Nacional, Quito - Ecuador, Candidato a Doctor en Gestión Tecnológica \\ aaldas@puce.edu.ec
}

\section{RESUMEN}

El objetivo de este ensayo es describir el desarrollo histórico del cooperativismo mundial y sus formas de organización y principios básicos sobre los que se asienta. Se presenta una breve descripción de los principales pensadores que contribuyeron al desarrollo y fortalecimiento del cooperativismo como forma alternativa de organización empresarial, que permite su supervivencia en el sistema capitalista, mientras conserva sus principios de solidaridad y justicia social. Se concluye que es posible una relación entre el cooperativismo y el desarrollo económico de las sociedades debido a que el cooperativismo es un sistema catalizador de la vida en sociedad y no sólo una simple forma de empresa. Mediante este ensayo se espera hacer una contribución para el replanteamiento y reconsideración del cooperativismo como forma de desarrollo social y económico en Latinoamérica.

Palabras clave: Cooperativismo, solidaridad, empresa, organización, justicia social

\section{ABSTRACT}

The objective of this article is to describe the historical development of global cooperativism and its forms of organization and basic principles on which it is based. It presents a brief description of the main thinkers who contributed to the development and strengthening of cooperativism as an alternative form of business organization, which allows them to survive in the capitalist system, while preserving their principles of solidarity and social justice. It is concluded that a relationship between cooperativism and the economic development of societies is possible because cooperativism is a catalyst for life in society and not just a simple form of business. Through this brief bibliographic review, it is hoped to contribute to the reconsideration of cooperativism as a form of social and economic development in Latin America.

Keywords: Cooperativism, solidarity, enterprise, organization, social justice 


\section{INTRODUCCIÓN}

Las variadas condiciones que el hombre ha tenido que experimentar a lo largo de su existencia, lo obligan a valerse de formas de organización social y económica. En la actualidad, con la división del trabajo y la especialización de las funciones (Taylor, 1911), el comportamiento del hombre es vital para lograr sus aspiraciones de desarrollo. Aquí es donde surgen las cooperativas que agrupan a las personas en torno a una empresa capaz de mejorar su situación socioeconómica, modificando el comportamiento individualista por la cooperación consciente y voluntaria de los interesados (Araya, Ayala, \& Benecke, 1980).

Según Gallardo (1977) el concepto de cooperativa se puede definir como: "un grupo de personas que se asocian en una forma libre y voluntaria con el propósito de rendirse servicios y rendirlo a la comunidad". Las cooperativas tienen un contenido social y un contenido económico, la ausencia de uno de estos contenidos impide el desarrollo estable de esta clase de organizaciones.

La cooperación es contraria al individualismo, pero no a la competencia, las cooperativas tienen determinadas etapas evolutivas, mediante las cuales tienden a considerar su medio ambiente, y lograr la eficiencia económica y la satisfacción de las necesidades de sus miembros (Araya et al., 1980). p. 110): "podría postularse como Objeto de Estudio de la Administración la ORGANIZACIÓN comprendida como un sistema social complejo, conformado por individuos que interactúan en formas particulares y dinámicas para el logro de determinados objetivos".
Desde una perspectiva administrativa el objetivo del presente ensayo es estudiar el desarrollo histórico de la forma organizacional cooperativista y así comprender mejor su funcionamiento, tanto en sus aspectos doctrinarios como empresariales. El interés está en conocer las condiciones de éxito de los grupos de cooperación y averiguar cuál es la motivación que impulsa a las personas a constituirlos y permanecer en ellos, cuáles son los principios que regulan su acción y las diferentes formas en que pueden implementarse.

Para Santos (2011) como teoría social el Cooperativismo es una forma alternativa válida de organización económica basada en la igualdad, la solidaridad y la protección del ambiente, el cooperativismo está basado en dos postulados: por un lado, la defensa de una economía de mercado con principios no capitalistas de cooperación y mutualidad, y por otro, la crítica al Estado centralizado y la preferencia por formas de organización política pluralistas, que den un papel central a la sociedad civil.

El paradigma funcionalista enmarca este estudio de teoría social, debido a que se presenta desde una perspectiva que está enraizada en la sociología de la regulación y el orden, y se enfoca el tema desde un punto de vista objetivista (Burrell \& Morgan, 1979).

El presente ensayo se ha dividido en tres partes, en la primera se realiza una descripción del surgimiento y desarrollo histórico del cooperativismo, en la segunda parte se realiza una descripción de los principios que rigen la organización de las cooperativas modernas, y en la tercera parte se describe la forma como se ha desarrollado el cooperativismo tanto en los 
países desarrollados como en vías de desarrollo, en especial se describe la evolución del cooperativismo en Latinoamérica.

\section{DESARROLLO}

\section{Surgimiento y desarrollo de la cooperación}

Desde que los hombres primitivos se establecieron en organizaciones sociales y económicas como las tribus, comienza un comportamiento que se aleja del individualismo y se manifiesta en diversas formas de cooperación. Por ejemplo, la cooperación en el trabajo agrícola surge por la necesidad de recibir la ayuda de otros campesinos para realizar la producción agrícola, que además reviste un carácter festivo (Gallardo, 1977).

Para Araya (1980) la revolución industrial, que sustituyó el sistema doméstico por la moderna producción fabril y convirtió a los artesanos que trabajaban con bastante libertad en asalariados sujetos a una estricta disciplina laboral, produciendo paulatinamente un empobrecimiento de éstos y un enriquecimiento de los industriales, es la causa fundamental del surgimiento de las ideas cooperativas.

Uno de los principales precursores de las ideas cooperativas fue Robert Owen, nacido en Inglaterra en 1771, es considerado el padre de la cooperación inglesa, se le considera como un industrial paternalista que vela por el bienestar de sus trabajadores al reducir la jornada de trabajo, aumentar los salarios e impartir educación gratuita. Desarrolla su teoría acerca de las aldeas cooperativas, como un camino para alcanzar una sociedad justa, y su teoría del valor de los bienes, del "justo precio", que considera que los bienes deberían transarse pagándolos con otros bienes o con bonos de trabajo (Arango, 2005).
William King, nacido en Inglaterra en 1786 y discípulo de Owen, tenía la visión de que el comercio era lo que generaba las grandes riquezas y, por lo tanto, los trabajadores debían organizarse en el consumo y no en la producción. Proclamaba la naturaleza voluntaria de la cooperación (Gallardo, 1977).

Charles Fourier, nacido en Francia en 1772, propone un plan de reforma social donde está presente la formación de comunidades donde exista una cooperación integral, sus ideas cooperativas se refieren más a resolver el problema de la producción que el de la distribución. Propone la formación de falanges (comunidades) instaladas en colonias, constituidas por personas de distinta clase social, riqueza y costumbre, donde se mantiene la propiedad individual y las preferencias personales (Araya et al., 1980).

Philippe Buchez, nacido en Francia en 1796, basa sus planes de reforma social en el cristianismo y en la ayuda propia, sin contar con un apoyo del Estado, ni de ricos filántropos. Las cooperativas de producción, serían una solución inmediata para los obreros calificados, los que aportarían sus herramientas y el dinero que dispusieran, además un $20 \%$ de las ganancias se destinaría a formar un capital social (Araya et al., 1980).

Lovis Blanc, nació en España en 1811, se le considera el precursor del socialismo democrático moderno, planteaba que el Estado debería planificar la economía y desarrollar los servicios públicos. Era enemigo de la lucha de clases, a la cual oponía la solidaridad, para buscar un nuevo orden social, con bases en el derecho al trabajo y su organización en asociaciones libres en las que se exigiese a cada uno según sus capacidades y se le retribuyese de acuerdo con sus necesidades (Arango, 2005). 
En las ideas de los precursores del cooperativismo encontramos ideas comunes que son la base de la organización y del funcionamiento de las cooperativas modernas (Arango, 2005):

- El esfuerzo conjunto trae mayores beneficios que el trabajo individual.

- El progreso de los diferentes grupos de cooperación debe realizarse sobre la base de la ayuda propia.

- En los grupos de cooperación el capital es solo un medio para alcanzar los objetivos de la organización.

- Las cooperativas son economías colectivas.

- Las cooperativas no son entidades aisladas, sino que forman parte de un gran movimiento cooperativo.

- El movimiento cooperativo es una organización que se va fortaleciendo con el tiempo y que promueve la formación de nuevas cooperativas.

\section{Organización de las cooperativas modernas}

A partir de la década de 1840 en Inglaterra, se fue formando un movimiento cooperativo, alejado de los conceptos de Owen y de las teorías de los economistas anticapitalistas. Este nuevo movimiento se orientó a la conformación de cooperativas de consumo con el fin de mejorar el nivel de vida de los trabajadores, lo que desembocó para 1844, en la constitución en Rochdale,
Inglaterra, de la cooperativa "Sociedad de los Justos Pioneros de Rochdale", en esta cooperativa supieron interpretar las ideas cooperativas existentes y formularon un conjunto de reglas prácticas y de organización, que explican el éxito de su cooperativa y las validez de sus ideas en las cooperativas actuales (Araya et al., 1980).

Los siete principios de acción originales del cooperativismo de Rochdale son en resumen los siguientes: 1) la libre asociación para todos aquellos que estén dispuestos a colaborar de buena fe; 2) cada socio tendrá derecho a un voto y nada más que a un voto; 3) el capital redituará un interés fijo; 4) los ahorros netos se distribuirán entre los socios según su proporción en el uso de bienes y servicios de la asociación; 5) toda transacción comercial se hará en efectivo y a precios justos; 6) periódicamente se hará una revisión de las cuentas y se rendirán informes; y 7) los socios celebrarán reuniones frecuentes para estudiar la marcha de la asociación (Bogardus, 1964).

Los siete principios cooperativos planteados en Rochdale, fueron acogidos por la Alianza Cooperativa Internacional (ACI) que en su versión aprobada en Manchester en 1995 son los siguientes (Arango, 2005): 1) adhesión voluntaria y abierta, 2) gestión democrática por parte de los asociados, 3) participación económica de los asociados, 4) autonomía e independencia, 5) educación, formación, capacitación e información, 6) cooperación entre cooperativas, y 7) interés por la comunidad.

Herman Schultze-Delitzsch (1806-1883) propuso un sistema de cooperación que fue adoptado por pequeños comerciantes, industriales y artesanos, que formaron asociaciones para abastecimiento, venta y consumo en común, pero fueron las 
asociaciones para el crédito común que alcanzaron el mayor éxito. Por su parte, Friedrich Raiffeisen (1818-1888) propuso un sistema cooperativo que está dirigido al sector rural y cuyas funciones se adaptaron a las características de la actividad agrícola (Araya et al., 1980).

El francés Charles Gide (1847-1932) colocó las cooperativas de consumo como la base para el desarrollo de un capitalismo social. Propone un programa para alcanzar una república cooperativa, mediante el desarrollo progresivo de los sectores cooperativos, tomando como base el consumo (Arango, 2005).

\section{Desarrollo y organización del cooperativismo en el} mundo

\subsection{El cooperativismo en países desarrollados}

El cooperativismo surgió en países desarrollados como una respuesta a los efectos de la revolución industrial de principios del siglo XIX, en los cuales se ha institucionalizado y se han asentado sus principios sin intervención del Estado ni de patronos. En Europa occidental el cooperativismo hace énfasis en la economía solidaria que da prioridad al factor trabajo sobre el factor capital (Arango, 2005).

Un caso de éxito en España es el complejo cooperativo Mondragón que empezó en 1965 y pertenece a los 30000 trabajadores de sus 109 fábricas, tiene su cadena de supermercados, su banco y su universidad. Las razones fundamentales de su éxito están relacionadas con la inserción de las cooperativas en redes de apoyo y con el esfuerzo constante para hacerlas competitivas en el mercado global (Santos, 2011).
Aunque el cooperativismo no ha alcanzado en Estados Unidos la importancia que en Europa Occidental, se ha desarrollado un importante sector cooperativo entre granjeros con actividades de comercialización y suministro de insumos, y servicios de ahorro y crédito. El grupo cooperativo Desjardins con cinco millones de socios tiene influencia en gran parte de Canadá. El cooperativismo ha contribuido a que Canadá sea uno de los países más prósperos del mundo, y en cierta medida han logrado contrarrestar los efectos del neoliberalismo en el campo de la justicia social y también ha permitido asumir compromisos solidarios con los discapacitados y ancianos (Arango, 2005).

De acuerdo con Garteiz (2011) las sociedades cooperativas no deben perder su norte que es el cambio social, la solidaridad y la justicia social, y su objetivo es demostrar que es posible una economía participativa y democrática.

\subsection{El cooperativismo en países en vías de desarrollo}

El modelo cooperativo en los países en vías de desarrollo fue impuesto de arriba hacia abajo en la mayoría de los casos, como resultado de políticas gubernamentales motivadas por organismos internacionales, lo cual derivó en empresas cooperativas marginales sin identidad ni protagonismo en los procesos sociales y económicos. En África, el cooperativismo ha tenido poco desarrollo debido a la inestabilidad política en sus Estados y a sus varios conflictos armados (Arango, 2005).

En Israel existe una economía cooperativa bastante desarrollada y organizada con los kibutz, que son comunidades cooperativas de producción agrícola eindustrial. El cooperativismo 
en China ayudó en su proceso de transformación a ser uno de los países más desarrollados del mundo (Arango, 2005).

Un ejemplo de éxito, es el caso en India de una cooperativa de productores de cigarros de Kerala, en donde los factores esenciales para sobrevivir frente a la competencia de las empresas capitalistas son una combinación de descentralización y colaboración entre cooperativas asociadas en red y la fidelidad al principio de participación democrática dentro de la cooperativa (Santos, 2011).

El cooperativismo llegó a Latinoamérica a finales del siglo XIX con la llegada de inmigrantes europeos a Argentina, Uruguay y Brasil. Sobre todo, en Argentina el cooperativismo alcanzó protagonismo en áreas como: producción agropecuaria e industrial, comercialización y exportación, ahorro y crédito, que llevó en la década de 1930 a que Argentina esté entre los 7 países más desarrollados del mundo (Arango, 2005).

A partir de la depresión de 1930, se impulsó el cooperativismo en Latinoamérica para enfrentar los efectos sociales de la crisis, bajo la orientación del gobierno norteamericano, se impulsaron cooperativas de consumo, ahorro y crédito, pero luego de treinta años los resultados fueron frágiles con pequeñas cooperativas carentes de ideología y principios, con poca influencia sobre la comunidad (Arango, 2005). creación de cooperativas de producción y comercialización. Dichos programas de reforma agraria fueron solamente de tipo marginal, porque no apuntaban a romper la estructura latifundista que impulsan programas de reforma agraria, estimulando la imperante, lo que condujo a otra frustración cooperativa por su imposibilidad de quebrar las estructuras agrarias de los países latinoamericanos heredadas de las haciendas coloniales (Arango, 2005).

Desde la década de 1980, en Latinoamérica se adopta el neoliberalismo, como propuesta de modernización del Estado y la sociedad, con la globalización económica y las leyes del libre mercado. En este proceso de implantación del modelo neoliberal, el cooperativismo se ve fuertemente afectado por su debilidad doctrinal e ideológica, la ausencia de modelos de desarrollo económico y social, el colapso del cooperativismo financiero y bancario, y su consiguiente afectación al resto de subsectores cooperativos, con la consiguiente desconfianza de los sectores populares frente al cooperativismo debido a que cientos de personas perdieron sus ahorros (Arango, 2005).

En Latinoamérica, la voluntad cooperativa en la mayoría de los casos depende del apoyo financiero externo, del Estado, de la Iglesia, de una ONG, o de créditos bancarios, pero cuando esa ayuda falta, se reduce la voluntad cooperativa entre los miembros y la membresía de las cooperativas disminuye (Quijano, 2011).

En el Ecuador el cooperativismo comenzó formalmente a inicios del siglo XX, con la creación de cooperativas de consumo, luego con la reforma agraria, se formaron cooperativas de producción y comercialización, luego con el neoliberalismo, las cooperativas sufrieron por la competencia feroz por ganar clientes. La pérdida de control y desinterés por parte del Estado contribuyeron a su división y debilitamiento. En 2011, entró en vigor la Ley Orgánica de Economía Popular y Solidaria

y del Sector Financiero Popular y Solidario, que pretende la 
reglamentación jurídica de las cooperativas y busca su fomento y desarrollo (Miño, 2013).

\section{CONCLUSIONES}

El cooperativismo representa una forma adecuada de participación de los sectores populares en la vida económica y social de un país, y permite medir su nivel de madurez democrática.

Las cooperativas pueden hacer posible una economía participativa y solidaria, produciendo un cambio social donde prime la justicia y la igualdad.

El incipiente desarrollo de las cooperativas en una sociedad es un síntoma del atraso político y social de los grandes sectores de la población, que continúan varados en regímenes colonialistas.

Para futuras investigaciones se recomienda estudiar el nivel de relación que tienen las Tecnologías de la Información y la Comunicación con el éxito y la permanencia en el tiempo de las organizaciones cooperativistas.

\section{REFERENCIAS BIBLIOGRÁFICAS}

Arango, M. (2005). Manual de cooperativismo y economía solidaria. Medellín: Universidad Cooperativa de Colombia.

Araya, R., Ayala, H., \& Benecke, D. (1980). Cooperación y Cooperativismo. Santiago de Chile: Ediciones Nueva Universidad.
Bogardus, E. (1964). Principios y problemas del cooperativismo. México: Libreros Mexicanos Unidos.

Burrell, G., \& Morgan, G. (1979). Sociological Paradigms and organisational Analysis - Elements of the Sociology of Corporate Life. Sociological Paradigms and Organisational Analysis, 448. https://doi.org/10.1177/003803858001400219

Gallardo, M. (1977). La cooperativa al alcance de todos. Quito: Talleres gráficos de la armada.

Garteiz, J. (201 1). Las cooperativas: una alternativa económica. Madrid: DYKINSON.

Hernández, A., Saavedra, J., \& Sanabria, M. (2007). Hacia la construcción del objeto de estudio de la administración: una visión desde la complejidad. Revista Facultad de Ciencias Económicas: Investigación Y Reflexión, XV(1), 91-112.

Miño, W. (2013). Historia del Cooperativismo en el Ecuador. Quito: Ministerio de Coordinación de la Política Económica.

Quijano, A. (2011). Sistemas alternativos de producción? In Producir para vivir (pp. 369-397). México: Civilizacao Brasileira.

Santos, B. de S. (2011). Producir para vivir. México: Civilizacao Brasileira.

Taylor, F. (1911). Principios De La Administracion Científica. Buenos Aires: El Ateneo. 